\title{
Exploring social innovation in health in Central America and the Caribbean
}

\author{
Josselyn Mothe, ${ }^{1}$ Luis E. Vacaflor, ${ }^{2}$ Diana M. Castro-Arroyave, ${ }^{2}$ Luis Gabriel Cuervo, ${ }^{1}$ and \\ Nancy Gore Saravia²
}

Suggested citation Mothe J, Vacaflor LE, Castro-Arroyave DM, Cuervo LG, Gore Saravia N. Exploring social innovation in health in Central America and the Caribbean. Rev Panam Salud Publica. 2020;44:e77. https://doi.org/10.26633/RPSP.2020.77

\begin{abstract}
Universal health coverage is a public health priority in the Americas. Social innovation in health offers novel solutions to unmet needs, by enabling health care delivery to be more inclusive, affordable, and effective. In 2017, an international collaborative consortium launched an open call for solutions that sought to identify social innovations in health in Central America and the Caribbean. The focus was set on how these solutions can strengthen health care delivery, with emphasis on reducing the impact of neglected transmissible diseases. A crowdsourcing strategy was implemented to identify social innovations in health. These were evaluated by an external panel of experts and practitioners and civil society representing the health and social innovation sectors, based on the appropriateness, innovativeness, and affordability of the solution. The three top-scoring solutions were analyzed through case studies including site visits by a team of investigators. Two key findings emerged from the response to the call: 1) innovative solutions were based on the knowledge and experience of individuals and communities facing adverse situations; 2) this knowledge was shared through health promotion and education, leading to empowerment of the communities. The principal challenges addressed by the solutions were the limited access to quality health care services and failed traditional strategies for vector control. The solutions identified demonstrated how social innovation can strengthen health systems by delivering novel solutions to health needs and articulating communities to enable them to work hand-in-hand with the health system toward universal health.
\end{abstract}

Keywords Neglected diseases; delivery of health care; social participation; Central America; Caribbean region.

Universal health coverage is one of the targets of the Sustainable Development Goals proposed in the United Nations 2030 Agenda for Sustainable Development, and is a public health priority in the Americas (1). Reaching this target consists in ensuring that every individual and community has access to quality health services without risking financial hardship (2). By 2017 an estimated 3.6 billion people, half of the world's population, did not have access to the health services they needed (3). Their unmet needs include those related to neglected tropical diseases (NTDs) affecting over a billion people worldwide and disproportionally impacting those living in poverty. NTDs pose a substantial challenge in Central America and the Caribbean.

Efforts to solve health needs have led to the development of guidelines and strategies. Yet these measures often fail to reach the target populations, which are frequently left out of the planning, development, and implementation of solutions developed as top-down approaches (4). Innovative social approaches offer participatory options to facilitate this process (5). This report highlights three examples of innovative social approaches, identified through a regional crowdsourcing strategy, that involve communities and other stakeholders

\footnotetext{
1 Pan American Health Organization, Washington, DC, United States of America. $\bowtie$ Josselyn Mothe, mothejosselyn@gmail.com
} 
in the design and implementation of contextually appropriate solutions.

Social innovation in health is manifested in many ways that illustrate the resilience of communities. It is defined as a "novel solution (process, product, practice, market mechanism) developed ... in response to a priority health need within a geographical context and implemented by different cross-sectoral organizations. [Such solutions have] enabled health-care delivery to be more inclusive, affordable and effective" (4).

Identifying these solutions is challenging because of their emergence in unique settings and circumstances outside of the mainstream. They tend to develop beyond the boundaries of the health system and frequently outside of institutional frameworks (6). Because the affected communities are often isolated or marginalized, their resilience and creativity is neither perceived nor studied and understood through a systematic approach. Consequently, literature on the topic is also scarce (7) and inequities persist. Yet, a characteristic of successful health systems is their capacity to be resilient and to learn from experience, and thereby feed back into the policy cycle, as well as achieve synergies among sectors and actors (8).

The Social Innovation in Health Initiative (SIHI) was launched in 2014 to explore and showcase innovative approaches to health care delivery developed by communities, and promote their assessment through the lens of research. This global collaborative initiative is supported by the Special Programme for Research and Training in Tropical Diseases (TDR), which is co-sponsored by UNICEF, UNDP, the World Bank, and the World Health Organization (WHO). It is aimed at identifying social innovations that address health systems challenges - with an emphasis on infectious diseases-through strategies promoting access to quality health services in vulnerable communities.

In 2015, SIHI developed and launched a global call for solutions in the "Global South" as a crowdsourcing strategy. While many solutions were identified in Asia and Africa, few responses were received from Latin America or the Caribbean. Based on the lessons learned from this call and the operational and technical guidance of SIHI, in 2017, a new, regional call was launched targeting Central America and the Caribbean (CAC). The call was championed by the Pan American Health Organization (PAHO/WHO) in collaboration with the Centro Internacional de Entrenamiento e Investigaciones Médicas (CIDEIM, TDR Regional Training Centre for the Americas) and Universidad Icesi in Cali, Colombia. Together, these institutions have constituted a regional hub for SIHI ${ }^{1}$ in Latin America and the Caribbean (SIHI LAC), whose goal is to investigate, increase awareness of, and advance social innovations in health in the CAC region.

This call focused on identifying and characterizing solutions that enhance access to primary care and disease prevention and control, especially in relation to NTDs. In this report we describe the methodology employed for the call, the lessons learned, as well as our insights into social innovation in health in the CAC region. We provide an overview of the three solutions that were recognized by the selection panel and interviews through the call and review process.

https://socialinnovationinhealth.org/americas /

\section{CROWDSOURCING TO IDENTIFY SOCIAL INNOVATION IN HEALTH, AND LESSONS LEARNED}

The call for innovation and applying crowdsourcing to identify social innovation. This regional endeavor ${ }^{2}$ was undertaken in two stages modelled on the SIHI global call of 2015 and adapted to the features and context of the CAC region. The first stage was a broad crowdsourcing call for innovative solutions and independent evaluation of the solutions. The second was the subsequent visits to the projects by investigators to amplify information, video record the experiences of the innovators, community, and stakeholders, and conduct case studies of the selected solutions (9).

Two key components of the call included the launch of a website and the creation of a dissemination database. The website hosted the application form and was the "window" to the call. The database encompassed three levels of entities. The first level was global, targeting international organizations, especially those involved in health and development (e.g., $\mathrm{PAHO} / \mathrm{WHO}$, the Organization of American States, the Inter-American Development Bank, and the World Bank) and organizations promoting innovation and research (e.g., WHO Collaborating Centres $\left.{ }^{3}\right)$. The second level consisted of national institutions, ranging from ministries of health to national education networks and national branches of global organizations (e.g., PAHO/WHO country offices). The third level comprised local entities, focusing on advocacy groups, municipal and state departments of health, health care providers, local NGOs, research centers, and higher education institutions. In addition, we sought engagement of key partners at all levels through social media (Twitter, Facebook, and LinkedIn).

The call was disseminated principally in English and Spanish and to a limited extent in French, the widely spoken languages in the target countries. The information was communicated using a range of materials including brochures, flyers, and email templates, which were shared with approximately 450 entities from the database, to increase the impact of the message and reach the relevant audience. Although we did not measure the return rate of these communications, Facebook messaging reached 17000 viewers in 20 countries. Nevertheless, reaching remote community leaders and NGOs was difficult and only partially achieved. Key performance indicator monitoring using Mailchimp has since been integrated into the SIHI LAC crowdsourcing communication strategy.

The website allowed applicants to submit their solutions in English and Spanish. Nevertheless, the announcement stated that applications in French were allowed, in order to include Haiti and other French-speaking territories/communities in the Caribbean region impacted by NTDs. Although resource and time constraints prevented support in a trilingual platform and evaluation process, an application from Haiti was received and presented in English. Following registration on the platform, an application consisting of 54 questions gathered contact and background information for the applicant and organization, and descriptions of: (i) the innovative solution; (ii) unique and innovative features of the solution in relation

\footnotetext{
The countries targeted were: Antigua and Barbuda, The Bahamas, Barbados, Belize, Costa Rica, Cuba, Dominica, Dominican Republic, El Salvador, Grenada, Guatemala, Haiti, Honduras, Jamaica, Nicaragua, Panama, Saint Kitts and Nevis, Saint Lucia, Saint Vincent and the Grenadines, Trinidad and Tobago.

3 https://www.who.int/about/who-we-are/structure/collaborating-centres
} 
to the problem addressed; (iii) problem addressed; (iv) the impact of the solution (i.e., effectiveness); (v) affordability; (vi) sustainability; (vii) usability and potential scalability; and finally (viii) involvement with other partners.

The call was initially launched for six weeks. The use of global organizations as a relay to disseminate the call proved to be instrumental in spreading the call across the region. Yet, despite the extensive dissemination effort, the limited initial response underscored the challenge of reaching target communities. Consequently, the communication strategy was adjusted to include a Facebook page with paid advertisement for target countries, and to extend the call to nine weeks. This led to the receipt of two additional applications. The innovative solutions originated in five countries: two from Guatemala, two from Honduras, and one each from El Salvador, Haiti, and Nicaragua.

Evaluation of innovations. Evaluations were conducted through a two-step process: screening for eligibility, followed by an external assessment by an independent panel. The principal reasons for ineligibility were the presentation of solutions by organizations in countries outside the target CAC region and innovations unrelated to infectious diseases.

The international and intersectoral expertise of the selection panel sought to engage recognized authorities within regional and international organizations whose mission includes social development, in order to assure credibility and prestige to the call and its outcome. The profiles of the eight members encompassed expertise in research for health, international development, entrepreneurship, and social innovation in public, intergovernmental, and private sectors. Members included a South American innovator recognized in the 2015 global SIHI call. Evaluation was based on six predefined criteria established by SIHI: appropriateness of the solution; innovativeness; inclusivity; affordability; scalability and potential for replication; and effectiveness. The selection panel used a guideline to score each of these criteria in a discrete Likert scale; scores were complemented with insights captured in a free text field.

On-site interviews and case studies of the highest-rated solutions were conducted as described in the SIHI protocol, to document and understand each innovation from the perspective of the innovators and the communities who adopted the solutions, and within their particular contexts. The protocol guiding the case studies was reviewed and approved by the Ethics Committee of CIDEIM. Data collection included direct observation and, in some cases, group and individual interviews. These interactions were recorded in audio, photo, or video formats. The SIHI framework proved to be an effective strategy that allowed an efficient use of resources and facilitated alignment with established standards.

\section{FINDINGS AND INSIGHTS IN SOCIAL INNOVATION IN HEALTH IN THE CAC REGION}

Sixteen applications were received. We present the principal findings of the call based on the seven solutions that fulfilled the eligibility criteria (geographic location of the health innovation, social nature of the solution, etc.).

Six applicants had a background in health: three were physicians, two were biologists, and one was an environmental health specialist. The other respondent studied international affairs and journalism. Among the respondents, five had an international background.
Among the seven qualifying solutions, three had been operating for less than three years and four had been operating for over five years. The applicant organizations were non-profit; four were NGOs and three were university based; two also self-described as social enterprises. The prominence of universities and the fact that many solutions were research-based or led by researchers could reflect a bias in the dissemination of the call, considering the social and educational missions and emphasis on public engagement of the organizations reached through the communication strategy to promote this initiative.

Regarding the innovative social solutions, four were focused on access to health care, and the other three on disease prevention, community engagement, and quality of health care, respectively. The target beneficiaries of the solutions were among the most vulnerable members of the community and most affected by limited access to health care: indigenous communities; isolated, rural, and under-resourced communities; and students, young parents, or children.

The primary source of funding was grant support, although one solution was financed by individual private donations. Engagement of local communities was reported in all seven eligible solutions. Importantly, a relationship with the public sector had also been developed in five of the eligible innovative solutions.

The communities principally faced two issues that motivated the innovations. The first was the limited presence of the health system and paucity of health care facilities. Poor access to health care was largely a result of scarce health care resources in hard-to-reach areas. The second issue was the failure of traditional prevention and control strategies, especially in relation to vector control, as was the case for two solutions focusing on prevention of Chagas disease.

\section{OVERVIEW OF THE SOCIAL INNOVATION FOR HEALTH SOLUTIONS SELECTED IN 2017}

Case study 1: Ecological approach to the control of native vectors of Chagas disease. Launched in 2004, this solution achieved sustainable prevention of Chagas disease in the Jutiapa rural region of Guatemala. There, houses are typically built using inexpensive locally available materials such as adobe, wood, and palm leaves, which provide refuge for parasite-transmitting triatomine bugs. This ecological approach to vector control focused on identifying and reducing three risk factors for household infestation that were related to the homes' characteristics and were susceptible to intervention: the unsanitary dirt floor, the adobe walls with cracks and crevices harboring triatomine bugs, and the permanent presence and rearing of animals inside the home. Together with the community and insight of professionals from different disciplines (architects, anthropologists, sociologists, engineers, and environmentalists), the solution devised was to fill and seal the crevices in the walls and surface of the floors using local, inexpensive materials. This strategy integrated the Mayan custom of habitations without windows, the use of locally available materials, and considered environmental constraints. Additionally, the awareness of risk factors was increased through the training of leaders and members of the community. Cultural considerations (e.g., the walls are cared for by women and the floors by men) were also taken into account.

The contextual community approach to problem-solving has created social value in the regions where the control strategy 
has operated, by effectively reducing the burden of vector infestation rates and lowering the frequency of infections, illness, and deaths (10). Additionally, a favorable cultural and behavioral change occurred in the communities, as manifested in the improved care and profitable use of the land surrounding the homes. Notably, several women in the community began cultivating fruit trees (mango, papaya, etc.) that generated additional income, increasing their economic standing and improving their quality of life (11). This initiative improved their household economy and reinforced empowerment through community-driven integrated vector control, further improving their quality of life and contributing to the sustainability of the innovation. The ecologic approach to vector control has been replicated in other regions of Guatemala, and some of its components reproduced in other countries, including El Salvador, Honduras, Mexico, and Nicaragua, funded by international agencies such as WHO, United States National Institutes of Health, and the Japan International Cooperation Agency.

Case study 2: Community-based participatory strategies to prevent Chagas in rural areas. The second selected innovative strategy focused on improving the diagnosis and treatment of Chagas disease at the Comapa Health Center in Guatemala. This innovation involved multiple institutions, was intersectoral (public, academic, and private sectors), and articulated capacities in diverse disciplines, especially involving the Comapa community members.

This inclusive strategy established a dynamic dialogue with the community to design a collaborative intervention having three steps: reducing reinfestations of the triatomine vector of Chagas disease in homes by motivating inhabitants to take an active role in the appropriate management of domestic animals (dogs, chickens, etc.), moving these outside of the house; training personnel in the local health center in the diagnosis of the disease; and reducing mother-to-child transmission of Chagas disease- a concern expressed by the community.

This innovation improved the articulation of vector control interventions by the municipality with the health care offered to Chagas patients. The Comapa Health Center played an active role in the attention and care of the population and reduced the risk of Chagas transmission in homes by combining strategies such as pesticide spraying, community education, and rodent control (12). This innovative initiative was supported by grants from international agencies such as WHO, the United States Centers for Disease Control and Prevention, and the International Development Research Centre of Canada. It delivered the evidence of impact that advanced the end goal of integrating the strategy into public policy, leading to its replication in other areas of Guatemala.

Case study 3: Shortening distances through telemedicine in Honduras. The third recognized innovation, based on volunteerism among health professionals and medical specialists and focused on telehealth, was developed in Gracias a Dios Department in Honduras. The project aims to improve access to health services for the Miskito community, living in one of the poorest regions of Honduras. This community experiences precarious living conditions, lack of potable water and electricity, and inadequate nutrition linked to low agricultural production and limited access to other food sources. The region has low accessibility to health care, exacerbated by the high cost of transportation from its remote location by plane or boat and a scarcity of basic medicines and technological services. Travel from the capital city Tegucigalpa to this community may cost more than flying overseas. The availability of telecommunication service in the locale provided an opportunity for this telemedicine initiative.

This innovation uses four strategies: 1) educational programs in rural areas to share solutions for health problems in the extended community; 2 ) videos in the native language addressing health topics delivered via television within the local hospital and other participating institutions; 3) telemedicine allowing consultations with physicians in an urban medical center using WhatsApp and mobile phone communication; 4) crowdsourcing to mobilize resources (e.g., medicines, transportation) (13).

This community-centered innovation reduced the costs of health services and consequent hardship incurred on family and community economies by providing remote consultation services and educating the inhabitants of the region in the management of low complexity health situations. During the period 2016-2017, approximately 350 cases of teleconsultation were reported, 20 patients were transferred to Tegucigalpa, approximately 2800 children benefited from the nutrition program, and 2500 patients received health care through health brigades. Community empowerment was also promoted by the participation of 600 community leaders and heads of families in the "Donde no hay doctor" course, a health education tool for communities located far from medical centers (14).

Further documentation of these case studies can be accessed at the SIHI Latin America case study collection (15) and in an article in the journal Infectious Diseases of Poverty (16).

Key lessons from social innovation in health solutions in Guatemala and Honduras. A common feature of the three recognized solutions was that knowledge transfer among the community and other actors was central to the development of local capacity and contributed to their sustainability. For the two innovations in Guatemala, learning together with the community was critical to raising awareness of the risk factors for colonization by Chagas disease vectors. The home improvement strategy and the capacity to implement these improvements were transferred to the community, and through the case studies we learned the rationale for the proposed solutions, the benefit of using local materials, and the culturally adequate strategies needed to implement the solutions. Capacity to perform the rapid test to diagnose Chagas and to promote awareness of the disease were transferred to the health personnel of local clinics and to midwives. In Gracias a Dios, Honduras, telehealth and on-site health brigades were key to providing training on basic care and leveraging $\mathrm{m}$-health among physicians and participating institutions, and to the long-term sustainability of the innovation.

\section{LIMITATIONS OF THE SIHI CALL FOR CENTRAL AMERICA AND THE CARIBBEAN REGION}

Despite limitations and difficulties, this exploration of social innovation for health opened a window on novel and resourceful approaches to health intervention in the CAC region. Limitations included the use of communication channels and language that are unfamiliar or inaccessible to remote or marginalized communities where dire necessity engenders creative solutions. Hence, the response to the call was low and 
likely underestimated initiatives in social innovation. Though powerful and far reaching, information and communication technology requires infrastructure that biases messaging to established "connected" organizations and institutions. Reaching community stakeholders will itself require alternative strategies of communication, including radio broadcasting. World Bank data ${ }^{4}$ on telecommunications coverage may inform the design of more inclusive outreach. Alternative means of communication with higher penetration in rural settings, such as radio, could improve ascertainment of social innovations for health. SIHI was designed to identify and promote communitybased solutions enhancing access to health. The descriptive results provide bases for developing tools and mobilizing resources to qualitatively and quantitatively investigate impact and social facilitators and barriers.

\section{CONCLUSION}

We found that successful social innovations were deeply rooted in the knowledge of the community, and that effective solutions built upon the knowledge and experience gained in seeking to address adversity and problems. Knowledge sharing across and between communities enabled the appropriation of solutions. Education was common to all the solutions and deemed essential to the efficiency and lasting impact of each innovation. Their sustainability relied on community ownership and engagement, and community leadership committed to improving health for everyone.

When traditional strategies and top-down approaches are failing, the solutions identified through the SIHI call in the CAC region illustrate the resourcefulness and potential of communities to strengthen health systems. These innovations provide a new and encouraging perspective of approaches to address old and engrained health problems. The innovations succeeded in addressing unmet needs and have the potential of being integrated into the health system, contributing toward the broader goal of universal access to health care.

Author contributions. JM led the planning, organization, and launch of the call, the collection and descriptive analysis of data, and drafted the manuscript. LEV supported the planning, organization, and conduct of the call, and participated

$\overline{4}$ https://data.worldbank.org/indicator/IT.NET.USER.ZS in descriptive analysis and drafting of the manuscript. DMCA contributed to the writing of the manuscript and analysis of the solutions. LGC reviewed the draft versions of the manuscript, provided insights on the country contexts of the innovations, and assisted in the deployment of the initiative in the CAC region. NGS assisted in the planning and organization of the call, participated in the development of the manuscript, wrote the SIHI LAC region proposal, and provided oversight of this initiative and its implementation. All authors reviewed and approved the final version.

Acknowledgment. We thank Maria Isabel Irurita (Universidad Icesi) and Lina Pinto Garcia (SIHI LAC) for their contribution in the design and conduct of the call and case studies; Dr. Lindi van Niekerk and Rachel Charter (SIHI) for their guidance in the implementation of the call in accordance with SIHI methods, tools, and standards; and Dr. Béatrice Halpaap (TDR) for her advocacy, resource mobilization, networking, and promotion of the SIHI initiative. We also thank PAHO Headquarters and PAHO country offices of the CAC region for their technical and logistical support, and Dr. Jackie Alger (Universidad Nacional Autónoma de Honduras) for supporting the dissemination of the call. We gratefully acknowledge the administrative support of Lina Jaramillo in the preparation of the call, and the international panelists, the communities, and social innovators for their vision and commitment to improving access to health.

\section{Conflicts of interest. None declared.}

Funding. The research project was supported by the Special Programme for Research and Training in Tropical Disease (TDR), co-sponsored by UNDP, UNICEF, the World Bank, and WHO. TDR is able to conduct its work thanks to the commitment and support from a variety of funders. For the full list of TDR donors, please see: https://www.who.int/tdr/about/ funding/en/. TDR receives additional funding from the Swedish International Development Cooperation Agency to support SIHI. The SIHI LAC regional hub is hosted in CIDEIM.

Disclaimer. Authors hold sole responsibility for the views expressed in the manuscript, which may not necessarily reflect the opinion or policy of the RPSP/PAJPH and/or PAHO. At the time when the call was done, JM interned at PAHO and LGC was Senior Advisor for Research Promotion and Development.

\section{REFERENCES}

1. Pan American Health Organization. Strategy for Universal Access to Health and Universal Health Coverage. CD53/5 Rev. 2 [Internet]. Washington DC: PAHO; 2014. Available from: https://iris.paho. org/xmlui/handle/123456789/28276

2. World Health Organization. The world health report: health systems financing: the path to universal coverage [Internet]. Geneva: WHO; 2010. Available from: https://www.who.int/whr/2010/en/.

3. World Health Organization; International Bank for Reconstruction and Development/World Bank. Tracking universal health coverage: 2017 global monitoring report [Internet]. 2017. Available from: https://www.who.int/healthinfo/universal_health_coverage/ report/2017/en/.

4. Van Niekerk L, Chater R, Naydenova E, Lim J, Chamas L, Manderson L, et al. Social innovation in health: case studies and lessons learned from low- and middle-income countries [Internet]. Geneva: World Health Organization; 2017:11. Available from: https://www.who. int/tdr/publications/year/2017/social-innovation-in-health/en/.

5. Halpaap BM, Tucker JD, Mathanga D, Juban N, Awor P, Saravia $\mathrm{NG}$, et al. Social innovation in global health: sparking location action. Lancet Glob Health. 2020;8(5):e633-e634. doi:10.1016/ S2214-109X(20)30070-X

6. Murray R, Caulier-Grice J, Mulgan G. The open book of social innovation: ways to design, develop and grow social innovation [Internet]. London: NESTA: Young Foundation; 2010. Available from: https:// youngfoundation.org/wp-content/uploads/2012/10/The-OpenBook-of-Social-Innovationg.pdf

7. Horgan D, Dimitrijević B. Social innovation systems for building resilient communities. Urban Sci. 2018;2:13. doi:10.3390/urbansci2010013 
8. Mills A. Health care systems in low- and middle-income countries. N Engl J Med. 2014;370:552-7. doi:10.1056/NEJMra1110897

9. Van Niekerk L, Hounsell R. Identifying social innovations through an open crowdsourcing call [Internet]. 1st ed. Geneva: Social Innovation in Health Initiative; 2016. 3rd ed. is available from: https:// socialinnovationinhealth.org/wp-content/uploads/2019/06/ SIHI_How-To-Guide_Identifying-Social-Innovations_v3_2017.pdf

10. Pellecer MJ, Dorn PL, Bustamante DM, Rodas A, Monroy MC. Vector blood meals are an early indicator of the effectiveness of the ecohealth approach in halting Chagas transmission in Guatemala. Am J Trop Med Hyg. 2013;88(4):638-44. doi:10.4269/ajtmh.12-0458

11. Irurita M, Pinto L. An eco-health approach to fight Chagas disease in Guatemala and beyond. Social Innovation in Health Initiative Case Collection [Internet]. Geneva: World Health Organization; 2018. Available from: https://socialinnovationinhealth.org/downloads/ Case_Studies/SIHI\%20LAC_Eco-health\%20approach $\% 20$ for $\% 20$ Chagas\%20Disease_Guatemala_2019.pdf

12. Pinto L, Irurita M. Comprehensive health approach for Chagas disease in Comapa (Jutiapa, Guatemala), Guatemala. Social Innovation in Health Initiative Case Collection [Internet]. Geneva: World Health Organization; 2018. Available from: https://social innovationinhealth.org/downloads/Case_Studies/SIHI\%20 LAC_Comprehensive $\% 20$ Approach $\% 20$ to\%20Chagas_Guatemala_ 2019.pdf
13. Castro D, Pinto L. Mosquitiamed: shortening distances through telemedicine. Social Innovation in Health Initiative Case Collection [Internet]. Geneva: World Health Organization; 2018. Available from: https://socialinnovationinhealth.org/downloads/Case_Studies / SIHI_LAC_MosquitiaMed_Honduras_2019.pdf

14. Werner D, Thuman C, Maxwell J. Donde no hay doctor: una guía para los campesinos que viven lejos de los centros médicos. 2nd ed. Berkeley, CA: Hesperian Foundation; 2010. Spanish.

15. Social Innovation in Health Initiative. Case Collection [Internet]. Geneva: World Health Organization; Available from: https: / / socialinnovationinhealth.org/innovations-from-latinamerica-the-caribbean/.

16. Castro-Arroyave D, Monroy MC, Irurita MI. Integrated vector control of Chagas disease in Guatemala: a case of social innovation in health. Infect Dis Poverty. 2020;9:25. doi:10.1186/ s40249-020-00639-w

Manuscript received on 1 November 2019. Revised version accepted for publication on 25 March 2020.

\section{Innovación social en materia de salud en América Central y el Caribe}

RESUMEN

Palabras clave
La cobertura universal de salud es una prioridad de salud pública en la Región de las Américas. La innovación social en materia de salud ofrece soluciones novedosas a las necesidades insatisfechas, al permitir que la prestación de servicios de salud sea más inclusiva, asequible y eficaz. En 2017, un consorcio de colaboración internacional lanzó una convocatoria abierta de soluciones con el fin de identificar innovaciones sociales en materia de salud en América Central y el Caribe. Esta se centró en la forma en que esas soluciones pueden fortalecer la prestación de atención sanitaria, con énfasis en la reducción de los efectos de las enfermedades transmisibles desatendidas. Para identificar las innovaciones sociales en materia de salud se aplicó una estrategia de colaboración masiva (crowdsourcing). Las propuestas fueron evaluadas por un grupo externo conformado por expertos, profesionales y la sociedad civil que representaban a los sectores de la salud y la innovación social, sobre la base de la idoneidad, la capacidad de innovación y la asequibilidad de la solución. Se analizaron las tres soluciones mejor calificadas mediante estudios de casos que incluyeron visitas al lugar por parte de un equipo de investigadores. De la respuesta a la convocatoria surgieron dos conclusiones clave: 1) las soluciones innovadoras se basaron en el conocimiento y la experiencia de las personas y las comunidades que se enfrentaban a situaciones adversas, y 2) este conocimiento se compartió a través de actividades de promoción de la salud y educación, lo que condujo al empoderamiento de las comunidades. Los principales problemas que abordaron las soluciones fueron el acceso limitado a servicios de atención sanitaria de calidad y el fracaso de las estrategias tradicionales de control de vectores. Las soluciones identificadas demostraron cómo la innovación social puede fortalecer los sistemas de salud proporcionando soluciones novedosas a las necesidades de salud y apoyando a las comunidades para que puedan colaborar estrechamente con el sistema de salud hacia la salud universal.

Enfermedades desatendidas; prestación de atención de salud; participación social; América Central; región del Caribe. 